\title{
Does the Efferent Auditory System Have a Role in Children with Specific Learning Disabilities?
}

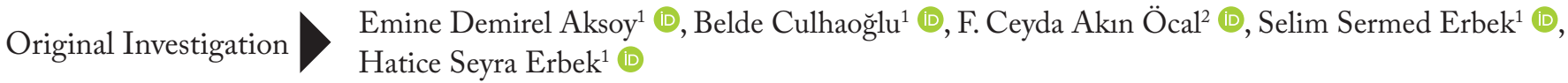 \\ ${ }^{1}$ Department of Otorhinolaryngology, Başkent University School of Medicine, Ankara, Turkey \\ ${ }^{2}$ Department of Otorhinolaryngology, Gülhane Training and Research Hospital, Ankara, Turkey
}

Abstract

ORCID IDs of the authors:

E.D.A. 0000-0002-0287-7717

B.C. 0000-0001-8121-8543;

F.C.A.0̈.0000-0001-7212-2208;

S.S.E. 0000-0003-4825-3499;

H.S.E. 0000-0002-8453-6069.

Cite this article as: Demirel Aksoy $E$,

Culhaloğlu B, Akın Öcal FC, Erbek SS, Erbek HS.

Does the Efferent Auditory System have a Role

in Children with Specific Learning Disabilities?

Turk Arch Otorhinolaryngol 2019; 57(1): 30-3.

This study was presented at the $13^{\text {th }}$ Turkish Rinology Congress, 5th National Neurootology Congress, $1^{\text {st }}$ Head and Neck Congress, May 2018, Antalya, Turkey.

Corresponding Author:

F. Ceyda Akın Öcal; fceydaakin@gmail.com

Received Date: 18.08.2018

Accepted Date: 23.12.2018

(c) Copyright 2019 by Official Journal of the Turkish

Society of Otorhinolaryngology and Head and

Neck Surgery Available online at

www.turkarchotolaryngol.net

DOI: 10.5152/ta0.2019.3748
Objective: This study aimed to compare the baseline transient otoacoustic emission ( $\mathrm{t}-\mathrm{OAE}$ ) amplitudes and medial olivo-cochlear (MOC) efferent activity in children with specific learning disability (SLD) and children with normal development.

Methods: The study was conducted in two groups. The patient group included 30 children aged 6 to 10 years and diagnosed with SLD, and the control group included 30 children in the same age range without SLD. The patient group included eight males and 22 females, and the control group included 14 females and 16 males. $\mathrm{t}-\mathrm{OAE}$ and contralateral suppression test were performed in both groups.

Results: In the first t-OAE measurements, a statistically significant difference was observed between the patient and the control group at frequencies of 1400 , 2000, 2800, and $4000 \mathrm{~Hz}$, but no such difference was observed at $1000 \mathrm{~Hz}$ frequency. In the control group, significantly better emission amplitudes were observed. No differences were found at any frequency between the patient and the control groups after suppression. When the subjects in the two groups were compared among themselves, there was a statistically significant difference between the before and after suppression scores in the patient group except at 4000 Hz. Likewise, an important difference was also observed in all frequencies in the control group.

Conclusion: This study shows that suppression effects of t-OAE on children diagnosed with SLD and children with no SDL are not significantly different.

Keywords: Otoacoustic emissions, specific learning disability, outer hair cell, medial olivo-cochlear response

\section{Introduction}

Specific learning disability (SLD) is a heterogeneous disorder that emerges with delay or deterioration in acquiring writing, speaking, reading, comprehension, or arithmetical skills (1). Children with SLD have normal IQ performance, and have no obvious causal factors, such as hearing loss or any neurological findings. Some behavioral studies show that speech perception problems may contribute to language problems in some children with SLD (2).

Otoacoustic emissions (OAE) are the sounds produced by the outer hair cells (OHCs) of the cochlea. OAE is measured with a microphone placed in the external ear canal (3). Reduced emissions in response to the presentation of noise from the contralateral ear indicates the existence of the medial olivo-cochlear (MOC) reflex $(4,5)$.This reduction, resulting from the action of the MOC system through the synapses in the $\mathrm{OHC}$, decreases the cochlear amplification gain, inhibits basilar membrane responses, and changes the amplitude of an OAE (5). The MOC efferents can be influenced by cortical activity, and play an important role in auditory plasticity (6). The MOC reflex activity enables our auditory system to adapt noises by reducing its response to a constant noise presence and to adapt our dynamic hearing range to the current environment. The contralateral MOC system efferents have direct effects on the function of the OHCs. In adults without hearing impairment, contralateral noise increases the ability to understand speech in noise. The defective MOC reflexes are considered to impair language acquisition by 
disturbing the separation of speech sounds from noises during critical periods of language acquisition, without considerable alterations in hearing thresholds (7).

A study conducted in 2003 showed that the auditory processing skills of children with SLD deteriorate in the background noise (8). Comprehension performance in noise was correlated with recipient and expressive language scores, which supported the relationship between language development and discriminating speech voices from noise. Thus, MOC deficits may provide a reasonable explanation for the language defect in these children. In 2017, Rocha-Muniz et al. (5) investigated the activation of an MOC efferent in children with poor speech-in-noise (PSIN) performance and children with language impairment (LI) and poor speech-in-noise PSIN (LI+PSIN). They found reduced OAE suppression compared to the typical development group. In a study conducted in 1999, a significantly lower OAE suppression was observed in 14 children with SLD than that observed in a normal hearing group (9). Yoshimura et al. (10) reported that acoustic auditory cortex plays an important role in language acquisition. The connections between the auditory cortex and the inner ear are provided by the medial olivo-cochlear system (MOCS) efferents.

This study aims to compare the MOC efferent activity and basal transient OAE between children with SLD and children with normal development.

\section{Methods}

In May and June 2016, 30 experimental subjects aged 6-10 years who were diagnosed with SLD $(8.26 \pm 1.04)$ and 30 subjects in the same age group with no SLD ( $7.66 \pm 0.92)$ as control group were included in the study. The experimental group consisted of eight males and 22 females, while the control group consisted of 14 females and 16 males. There was no significant difference in age and gender between the two groups ( $\mathrm{p}=0.112$ and 0.286 , respectively). Ethics committee approval was obtained from Başkent University School of Medicine (No: KA16/161). Consent forms were obtained from the parents. Inclusion criteria included the following: (1) normal otoscopy; (2) pure tone audiometry (PTA) thresholds $20 \mathrm{~dB}$ HL bilaterally; (3) normal tympanometry; (4) existence of t-OAE in both ears; (5) normal contralateral acoustic reflex; and (6) no systemic disease. Diagnosis of SLD was made with the Gessel Development Figures Test and the Bender Gestalt Visual Motor Sensitivity Test.

Table 1. The first transient-evoked otoacoustic emission measurements

\begin{tabular}{l|c|c|c}
\hline Frequency & $\begin{array}{c}\text { Patient Group } \\
\text { Mean } \pm \text { SD }\end{array}$ & $\begin{array}{c}\text { Control Group } \\
\text { Mean } \pm \text { SD }\end{array}$ & $p$ \\
\hline 1000 & $3.00 \pm 6.87$ & $6.02 \pm 5.96$ & 0.011 \\
\hline 1400 & $4.43 \pm 7.52$ & $9.28 \pm 6.04$ & $<0.001$ \\
\hline 2000 & $2.35 \pm 6.84$ & $7.64 \pm 6.77$ & $<0.001$ \\
\hline 2800 & $2.89 \pm 7.04$ & $7.97 \pm 7.65$ & $<0.001$ \\
\hline 4000 & $2.98 \pm 7.57$ & $8.09 \pm 6.89$ & $<0.001$ \\
\hline
\end{tabular}

\section{Procedure}

Transient OAE (t-OAE) tests (Titan; Interacoustics, Assens, Denmark) were performed in a quiet room. The parameters were non-linear click stimuli; intensity $80 \pm 3 \mathrm{~dB}$ sound pressure level (SPL); frequency bands $1,1.4,2,2.8,4 \mathrm{kHz}$; reproducibility over $65 \%$; and stimulus stability over $70 \%$ in the tested frequency; transient impulses averaged 260 times and $20-\mathrm{ms}$ window. The signal/noise ratio was considered significant at $3 \mathrm{~dB}$ SPL or $>3$ $\mathrm{dB}$ SPL. To investigate t-OAE suppression, a white noise was presented contralateral to the tested ear at $70 \mathrm{~dB}$ SPL. The test was applied in two steps. t-OAEs were recorded without and with contralateral noise. Suppression amounts were derived by subtracting the emission levels with contralateral noise from the emission levels without contralateral noise at all the frequency bands (11). t-OAE and suppression tests were applied by two audiologists who were unaware about the group types.

\section{Statistical Analysis}

Data were analyzed using the Statistical Package for the Social Sciences version 23.0 (IBM Corp.; Armonk, NY, USA). Intra-group comparisons were made using the paired t-test, and intergroup comparisons using the Student t-test. Variables were examined at $95 \%$ confidence level, and $p$ value $<0.05$ was considered as statistically significant.

\section{Results}

In the first t-OAE measurements, a statistically significant difference was observed between the patient and the control group at frequencies of $1400,2000,2800$, and $4000 \mathrm{~Hz}$, but no such difference was observed at $1000 \mathrm{~Hz}$ frequency. In the control group, significantly better emission amplitudes were observed (Table 1). No significant differences were found in the patient and control groups after the suppression at any frequency levels (Table 2). When the subjects in the two groups were compared among themselves, there was a statistically significant difference between the before and after suppression scores in the patient group except at $4000 \mathrm{~Hz}$. Likewise, an important difference was observed in the control group (Table 3).

\section{Discussion}

Specific learning disability is often associated with auditory processing disorders, but the relationship between them is not clear (12). Contralateral suppression may provide an objective and non-invasive clinical approach to study the MOCS and the descending auditory efferent pathways in the brainstem (13).

Table 2. Suppression values of patient and control groups

\begin{tabular}{l|c|c|c}
\hline Frequency & $\begin{array}{c}\text { Patient Group } \\
\text { Mean } \pm \text { SD }\end{array}$ & $\begin{array}{c}\text { Control Group } \\
\text { Mean } \pm \text { SD }\end{array}$ & $p$ \\
\hline 1000 & $1.56 \pm 3.9$ & $1.62 \pm 4.43$ & 0.936 \\
\hline 1400 & $0.85 \pm 2.92$ & $1.38 \pm 2.44$ & 0.281 \\
\hline 2000 & $1.25 \pm 1.86$ & $0.75 \pm 1.33$ & 0.095 \\
\hline 2800 & $0.85 \pm 2.17$ & $0.60 \pm 1.33$ & 0.449 \\
\hline 4000 & $0.13 \pm 2.89$ & $0.62 \pm 1.54$ & 0.25 \\
\hline
\end{tabular}


Table 3. Otoacoustic emissions before and after contralateral suppression in patient and control groups

\begin{tabular}{l|c|c|c}
\hline & \multicolumn{3}{|c}{ Patient Group } \\
\hline Frequency & Before CLS TEOAE & After CLS TEOAE & $\mathrm{p}$ \\
\hline 1000 & $3.00 \pm 6.87$ & $1.43 \pm 6.43$ & 0.003 \\
\hline 1400 & $4.43 \pm 7.52$ & $3.58 \pm 6.53$ & 0.028 \\
\hline 2000 & $2.35 \pm 6.84$ & $1.09 \pm 6.85$ & $<0.001$ \\
\hline 2800 & $2.89 \pm 7.04$ & $2.03 \pm 7.00$ & 0.003 \\
\hline 4000 & $2.98 \pm 7.57$ & $2.85 \pm 6.89$ & 0.723 \\
\hline & Control Group & & \\
\hline Frequency & Before CLS TEOAE & After CLS TEOAE & $p$ \\
\hline 1000 & $6.02 \pm 5.96$ & $4.40 \pm 6.17$ & 0.006 \\
\hline 1400 & $9.28 \pm 6.04$ & $7.89 \pm 6.32$ & $<0.001$ \\
\hline 2000 & $7.64 \pm 6.77$ & $6.88 \pm 6.77$ & $<0.001$ \\
\hline 2800 & $7.97 \pm 7.65$ & $7.37 \pm 7.48$ & 0.001 \\
\hline 4000 & $8.09 \pm 6.89$ & $7.47 \pm 6.72$ & 0.003
\end{tabular}

CLS: Contralateral suppression; TEOAE: Transient-evoked otoacoustic emissions

This study aimed to evaluate the efferent auditory system by contralateral suppression test of children with SLD. The main finding of this study is that there is no significant difference in the t-OAE results of children with SLD compared to that in normal children after contralateral suppression.

It is suggested that the medial efferent system improves the frequency decoding capacity and the discrimination of vowels especially in noisy environments $(13,14)$. Many studies in the literature show decreased activity of the MOC system in children with auditory processing disorders $(14,15)$. However, there are contradictory studies on MOC reflex in children with SLD.

The first finding in this study was that the t-OAE amplitudes in the control group were significantly higher than those in the patient group. Mishra (14) found higher amplitude t-OAEs in children with auditory processing disorders compared with control subjects. Veuillet et al. (9) found lower emission levels in children with SLD compared to those in the control group. Garinis et al. (16) conducted a study on 18 adolescents with and 18 control adults without a learning disability. They observed lower amplitude t-OAEs in the learning disability group compared to those in the control group. Though lower amplitudes of the learning disability group may indicate weaker $\mathrm{OHC}$ or cochlear function, the pure tone threshold below $20 \mathrm{~dB}$ is used for acceptance in both the control and the learning disability groups to exclude the peripheral effects on t-OAE. In this study, PTA at $20 \mathrm{~dB}$ and below was defined as a criterion for inclusion in the study. Low amplitude $\mathrm{t}-\mathrm{OAE}$ responses in the learning disability group compared to those in the control group may be due to the differences in the amount of MOC bundle control applied to OHCs. That the $\mathrm{t}-\mathrm{OAE}$ test depends mainly on the proper functioning of the $\mathrm{OHC}$ brings to mind whether this is caused by a peripheral auditory impairment in individuals with SLD. With this study, it may be speculated that the peripheral auditory system of the children with SLD functions less than that of the healthy children.
In this study, there also was a statistically significant difference in the control group before and after the contralateral suppression; while a significant difference was also observed in the $\mathrm{pa}^{-}$ tient group before and after the suppression except at $4000 \mathrm{~Hz}$ frequency. However, there was no significant difference between patient and control group after suppression. This result is similar to that of Butler et al. (17). Despite the age and the gender similarities of the two groups, the reasons for the absence of differences in post-inhibition emission amplitudes between the two groups are not yet known. However, wider studies to be conducted on children with SLD and normal children in the future may enable us to identify these reasons by evaluating different measurements of contralateral inhibition using t-OAEs or distortion product emissions (DPOAEs). The result we found is complicated by potential confounding variables related to the MOC inhibition measurements. Some studies, such as ours, use the non-linear click method, while some other studies use the linear click method that assesses both the linear and non-linear part of the MOC inhibitory response (11, 18). Mishra and Lutman (18) reported that the non-linear click method did not represent the overall amplitude of the MOC inhibitor response but removed artifacts in click-evoked OAEs. Some studies used either click- evoked or distortion product (DP) OAEs with contralateral acoustic stimulation to measure the MOC reflex. Measurement of contralateral inhibition extends the use of OAEs beyond the assessment of the function of OHCs alone. When more research is available, the clinical benefits of these measures will improve as we increase our understanding of inter-subject variability. We can better identify the normal efferent system function using OAEs.

The limitations of this study are that the study group is specific, the contralateral inhibition was assessed with non-linear click $\mathrm{t}-\mathrm{OAE}$, and the sample size is small.

\section{Conclusion}

This study aimed to compare the MOC efferent activity between children with SLD and children with normal development. The main finding of this study is that there is no significant difference in the t-OAE results in children with SLD compared to that in normal children after contralateral suppression. Auditory efferent system studies with larger SLD populations may help to understand the underlying mechanisms of $\mathrm{LD}$, and to that end, detailed evaluation must be performed in these children.

Ethics Committee Approval: Ethics committee approval was received for this study from the Ethics Committee of Başkent University School of Medicine (No: KA16/161).

Informed Consent: Written informed consent was obtained from the parents of the patient.

Peer-review: Externally peer-reviewed.

Author Contributions: Concept - S.S.E.; Design - E.D.A.; Supervision - F.C.A.O., S.S.E.; Resource - H.S.E., S.S.E.; Materials - E.D.A.; Data Collection and/or Processing - E.D.A., B.Ç.; Analysis and/or Interpretation - F.C.A.Ö.; Literature Search - F.C.A.Ö., B.Ç.; Writing - F.C.A.Ö., H.S.E.; Critical Reviews - S.S.E., H.S.E. 
Conflict of Interest: The authors have no conflicts of interest to declare.

Financial Disclosure: The authors declared that this study has received no financial support.

\section{References}

1. McDowell M. Specific learning disability. J Paediatr Child Health 2018; 54: 1077-83. [CrossRef]

2. Wright BA, Lombardino LJ, King WM, Puranik CS, Leonard CM, Merzenich MM. Deficits in auditory temporal and spectral resolution in language impaired children. Nature 1997; 387: 176-8. [CrossRef]

3. Kemp DT. Stimulated acoustic emissions from within the human auditory system. J Acoust Soc Am 1978; 64: 1386-91. [CrossRef]

4. Iliadou VV, Weihing J, Chermak GD, Bamiou DE. Otoacoustic emission suppression in children diagnosed with central auditory processing disorder and speech in noise perception deficits. Int J Pediatr Otorhinolaryngol 2018; 111: 39-46. [CrossRef]

5. Rocha-Muniz CN, Mamede Carvallo RM, Schochat E. Medial olivocochlear function in children with poor speech-in-noise performance and language disorder. Int J Pediatr Otorhinolaryngol 2017; 96: 116-21. [CrossRef]

6. Guinan JJ Jr. Olivocochlear efferents: Their action, effects, measurement and uses, and the impact of the new conception of cochlear mechanical responses. Hear Res 2018; 362: 38-47. [CrossRef]

7. Clarke EM, Ahmmed A, Parker D, Adams C. Contralateral suppression of otoacoustic emissions in children with specific language impairment. Ear Hear 2006; 27: 153-60. [CrossRef]

8. Stollman MH, van Velzen EC, Simkens HM, Snik AF, van den Broek P. Assessment of auditory processing in 6-year-old language-impaired children. Int J Audiol 2003; 42: 303-11. [CrossRef]
9. Veuillet E, Collet L, Bazin F. Objective evidence of peripheral auditory disorders in learning-impaired children. Journal of Audiological Medicine 1999; 8: 18-29.

10. Yoshimura Y, Kikuchi M, Ueno S, Shitamichi K, Remijn GB, Hiraishi $\mathrm{H}$, et al. A longitudinal study of auditory evoked field and language development in young children. Neuroimage 2014; 101: 440-7. [CrossRef]

11. Joffily L, de Melo Tavares de Lima MA, Vincent MB, Frota SM. Assessment of otoacoustic emission suppression in women with migraine and phonophobia. Neurol Sci 2016; 37: 703-9. [CrossRef]

12. Canale A, Dagna F, Favero E, Lacilla M, Montuschi C, Albera R. The role of the efferent auditory system in developmental dyslexia. Int J Pediatr Otorhinolaryngol 2014; 78: 455-8. [CrossRef]

13. Mertes IB, Wilbanks EC, Leek MR. Olivocochlear efferent activity is associated with the slope of the psychometric function of speech recognition in noise. Ear Hear 2018; 39: 583-93. [CrossRef]

14. Mishra SK. Medial efferent mechanisms in children with auditory processing disorders. Front Hum Neurosci 2014; 8: 860. [CrossRef]

15. Burguetti FAR, Carvallo RMM. Efferent auditory system: its effect on auditory processing. Braz J Otorhinolaryngol 2008; 74: 737-45. [CrossRef]

16. Garinis AC, Glattke T, Cone-Wesson BK. TEOAE suppression in adults with learning disabilities. Int J Audiol 2008; 47: 607-14. [CrossRef]

17. Butler BE, Purcell DW, Allen P. Contralateral inhibition of distortion product otoacoustic emissions in children with auditory processing disorders. Int J Audiol 2011; 50: 530-9. [CrossRef]

18. Mishra SK, Lutman ME. Repeatability of click-evoked otoacoustic emission based medial olivocochlear efferent assay. Ear Hear 2013; 34: 789-98. [CrossRef] 